\title{
Zopiclone and Prazepam Abuse in a Chronic Migraine Patient
}

\author{
Anna Ferrari $^{\mathrm{a}, \mathrm{c}}$, Ilaria Tiraferria ${ }^{\mathrm{a}}$, Federica Palazzolib ${ }^{\mathrm{b}}$, Manuela Licata ${ }^{\mathrm{b}}$
}

\begin{abstract}
Painful conditions are frequently accompanied by sleep disorders. Here we present the case, never previously reported, of high doses of zopiclone and prazepam abuse in a patient suffering from migraine and insomnia. A 37-year-old female Caucasian patient, nursing degree, with two 7-year-old twin daughters, began to suffer from migraines in her childhood. Migraine worsened and was associated with insomnia after the daughters' birth. Eight months ago, migraine and insomnia further worsened in conjunction with the prescription of fluoxetine and prazepam as migraine prophylaxis and of zopiclone for insomnia. From that moment, the patient increased the dose of zopiclone up to 20 tablets $(150 \mathrm{mg})$ nightly and prazepam up to 20 tablets $(400 \mathrm{mg})$ daily. As acute migraine treatment she also used ketorolac 1-2 f every day intramuscularly. The patient was hospitalised for withdrawal of medications and to treat migraine. Hair analysis documented the history of this patient and the good progress of the treatment. Zopiclone and prazepam are considered drugs with low abuse potential. However, the final outcome of a drug treatment may be influenced by non-drug factors, such as the patient's characteristics and the treatment milieu. In fact, in a stressful context, the prescription of zopiclone in a patient vulnerable for migraine triggered abuse of this drug and of prazepam, which was associated with chronification of migraine and analgesics overuse, without relieving insomnia. In prescribing hypnotics and anxiolytics to patients with chronic pain there must therefore be great caution.
\end{abstract}

Manuscript accepted for publication May 24, 2012

\footnotetext{
${ }^{a}$ Headache and Drug Abuse Inter-Dep. Research Centre, Division of Toxicology and Clinical Pharmacology, University of Modena and Reggio Emilia, Italy

${ }^{\mathrm{b}}$ Legal Medicine - Forensic Toxicology Laboratory, University of Modena and Reggio Emilia, Italy

${ }^{c}$ Corresponding author: Anna Ferrari. Headache and Drug Abuse Inter-Dep. Research Centre, Division of Toxicology and Clinical Pharmacology, University of Modena and Reggio Emilia, Policlinico, Largo del Pozzo, 71 - 41100 Modena, Italy.

Email: anna.ferrari@unimore.it
}

doi: $10.4021 / \mathrm{jmc} 729 \mathrm{w}$
Keywords: Zopiclone; Prazepam; Ketorolac; Insomnia; Abuse; Hair; Migraine; Medication-Overuse Headache; $\mathrm{MOH}$

\section{Introduction}

Sleep disorders are frequently associated to painful conditions. Moreover, there is a reciprocal relationship between pain and sleep: disturbed sleep has the potential to decrease the pain threshold whereas the pain threshold is increased during deep sleep [1]. Insomnia is the most common sleep disorder in headache clinic population, observed in $2 / 3$ of migraineurs [2]. Migraine affects $10 \%$ of the global adult population [3]. In a subgroup of patients, migraine may be a progressive disorder to become chronic (headache that occurs on $\geq 15$ days per month for at least 3 months [4]) and complicated by medication-overuse headache $(\mathrm{MOH})$, a daily headache due to excessive intake of acute medications, which improves with the discontinuation of the overused medication [5]. Both chronic migraine and insomnia are conditions that reduce the quality of life with mutual reinforcement and there is clinical evidence that the treatment of sleep disorders may improve migraine and the quality of life [2, 6]. Here we report a case of a migraine patient in whom the treatment of insomnia, instead, had worsened both of them, causing an increasing spiral of problems.

\section{Case Report}

A Caucasian, 37-year-old female patient, married, with 2 twin daughters of 7 years, professional nursing degree, began to suffer from migraines at the age of 6 years (her paternal grandmother suffered from migraine). With puberty, migraine became perimenstrual, then disappeared during pregnancy, but it returned and became more serious after childbirth. At the same time, she began to have difficulty in falling asleep and frequent nocturnal awakenings, also for severe migraine attacks that woke her up in the last hours of the night. She went to several neurologists, the diagnosis of migraine without aura according to the criteria of the In- 
ternational Classification of Headache Disorders (ICHD-II) [4] was made, and various prophylactic treatments were prescribed (she remembered flunarizine, atenolol, propranolol, gabapentin, and amitriptyline) without benefits.

Eight months ago, the last consulted neurologist prescribed her fluoxetine $20 \mathrm{mg} 1$ tablet and prazepam $20 \mathrm{mg}$ 1 tablet in the morning as prophylaxis of migraine and ketorolac $30 \mathrm{mg} 1 \mathrm{f}$ intramuscularly as acute treatment of migraine attack. He also prescribed zopiclone $7.5 \mathrm{mg} 1$ tablet in the evening to treat insomnia. Since then, headache and insomnia worsened and the patient rapidly increased the dosages of both zopiclone and prazepam. About 3 months before, her family doctor had replaced fluoxetine (which the patient deemed responsible for the worsening of migraine) with citalopram $20 \mathrm{mg} 1$ tablet per day.

When she came to our observation, migraine was chronic and associated with analgesics overuse (ketorolac $30 \mathrm{mg} 1-2 \mathrm{f}$ i.m. per day). For at least 6 months she had been taking zopiclone 20 tablets $(150 \mathrm{mg})$ every evening and prazepam 20 tablets $(400 \mathrm{mg})$, divided over every day. She was hospitalised for detoxification from anxiolytics and hypnotics abuse, analgesic medications withdrawal, and to treat migraine. At the admission, the patient appeared really suffering and was very concerned about her condition. Her physical health screen, lab tests, ECG, and brain MRI did not reveal any abnormalities. The standard blood and urine toxicological tests proved only positive for benzodiazepines. A first hair specimen was collected. Psychiatric counselling found a moderately deflected mood and reported discomfort in relational and family context because of migraine and insomnia. The patient had no previous history of psychoactive substance abuse.

During in-patient treatment, prazepam and zopiclone were gradually reduced; to treat headache and prevent withdrawal symptoms, delorazepam in decreasing dosages from $2 \mathrm{mg}$ to $0.4 \mathrm{mg} /$ day and ketoprofen $100 \mathrm{mg}$ for intravenous infusion were administered. After the first week, ketoprofen was only administered when needed and a prophylactic therapy of migraine was followed, with topiramate $25 \mathrm{mg}$ in the evening and (on the basis of a psychiatric consultation) mirtazapine $15 \mathrm{mg}$ in the evening. The patient did not present severe withdrawal symptoms. She had intense internal agitation, abdominal pain, fatigue, and intense and profuse sweating. At discharge, after 3 weeks, both headache and insomnia had improved, but she still took 4 tablets of prazepam/day, 4 tablets of zopiclone in the evening, topiramate $50 \mathrm{mg} / \mathrm{day}$, and mirtazapine $30 \mathrm{mg}$ at night. A program of further gradual reduction of prazepam and zopiclone and of increment of topiramate was prescribed. Rizatriptan $10 \mathrm{mg} 1$ tablet and/ or ketoprofen $100 \mathrm{mg}$ intramuscularly was recommended as acute migraine therapy.

At 2-month follow-up, she reported that headache was no longer daily and responded to rizatriptan. She slept better, at least 5-6 hours continuously per night. She was taking 
zopiclone 2 tablets in the evening, prazepam 2 tablets per day, topiramate $50+50 \mathrm{mg} /$ day, and mirtazapine $30 \mathrm{mg} /$ day . Blood and urine toxicological tests were still positive for benzodiazepines. Blood levels of topiramate were $5.3 \mathrm{mcg} /$ $\mathrm{ml}$. A second sample of hair was collected. The drugs in the hair were detected by liquid chromatography/electrospray tandem mass spectrometry [LC/ESI-MS/MS (Agilent technology, Palo Alto, CA, USA)]. The results of hair analysis (Table 1) confirmed the patient's pharmacological history and her adherence to the prescribed treatment. Then, the patient asked to be followed by a specialist neurologist of her choice, closer to where she lived. At a phone control, after 4 months, she reported to be better, since both insomnia and migraine had further decreased. She was taking zopiclone 1 tablet in the evening and prazepam 1 tablet in the morning. Topiramate had been discontinued for intolerable paresthesias and replaced with timolol $10 \mathrm{mg} 1$ tablet in the morning. Mirtazapine had also been suspended for excessive sedation and replaced with amitriptyline $50 \mathrm{mg}$ at night.

Written informed consent was obtained from the patient for publication of this case report.

\section{Discussion}

The final outcome of a pharmacological treatment can be strongly influenced by non-drug factors, such as individual characteristics and milieu [7]. In the case described, the attempt to solve two interconnected conditions - insomnia and migraine - had paradoxically complicated both rather than resolve them. The prescription of two drugs with low abuse potential, zopiclone and prazepam, to a vulnerable migraine patient in a stressful environment had prompted an escalation of abuse of both drugs up to doses 20 times higher than the therapeutic ones and further worsening and complicating of migraine, without relieving insomnia.

Zopiclone is a short-acting non-benzodiazepine hypnotic. At a dose of $7.5 \mathrm{mg} /$ evening, it is indicated for short-term therapy (up to 4 weeks) of insomnia [8]. When zopiclone was marketed, considering the results of short term clinical trials, it was considered less liable to dependence compared with benzodiazepines [9]. However, the ability of zopiclone to induce dependency is not zero. In a minority of people, rebound symptoms may occur that, although minimal, can perpetuate the use of the drug [10]. For its cross-reactivity with benzodiazepines, zopiclone has been successfully used as a facilitator to withdrawn the chronic use of benzodiazepines [11]. But in the case described, the opposite had occurred: the abuse of this drug had conducted to the abuse of prazepam, an anxiolytic benzodiazepine with long duration of action.

Prazepam is a pro-drug. In the first- pass metabolism, it is transformed into nordazepam, active and responsible for the therapeutic effects. The recommended dosage is 20 to 40 $\mathrm{mg} /$ day for up to 12 weeks. Prazepam can induce tolerance and physical dependence, but less severe than other benzodiazepines [12]. It appears to be a useful drug for the treatment of the anxiety state following narcotic withdrawal [13]. In our patient, it is likely to have initially acted in a similar way, as a treatment of rebound symptoms, daytime anxiety, and insomnia. Then, because of the development of tolerance and also cross-tolerance with zopiclone, it may have facilitated the increment of the doses of zopiclone up to 20 tablets $(150 \mathrm{mg})$ nightly, with exacerbation of rebound symptoms and resulting in a further increase of prazepam up to 20 tablets $(400 \mathrm{mg}$ ) daily. All this had happened without solving insomnia. Indeed, in patients with chronic migraine and medication overuse insomnia improves along with decrease in frequency and severity of headache by stopping medication overuse [14]. The story of our patient was in agreement with these observations.

In this patient, the initial use of zopiclone and prazepam was appropriate. She arrived to abuse of very high doses of these drugs not to achieve an effect of high, but with the sole goal of symptom relief. The patient had failed to stop the abuse because, when attempting, migraine, anxiety and insomnia amplified to a level that was incompatible with her family and work duty, but she had a strong desire to resolve her condition. Maybe this was the key factor for the success of the withdrawal. Indeed, hair analysis (Table 1) demonstrated the reliability of the patient's report on previous medication use and her compliance with treatment over time. In the first specimen of hair we found in the proximal segment, indicating the most recent use, concentrations of $6.68 \mathrm{ng} / \mathrm{mg}$, a thousand times greater than the $66 \mathrm{pg} / \mathrm{mg}$ measured in a chronic consumer of zopiclone $7.5 \mathrm{mg}$ /day for 1 year [15]. At the follow-up visit, in the second specimen of hair, in the proximal segment, zopiclone was absent, prazepam and its metabolite, nordiazepam, had decreased, and the medications we had administered and prescribed (delorazepam, topiramate, and mirtazapine) were detected.

The patient attributed the beginning of the escalation in the use of zopiclone and prazepam to the worsening of migraine after the prescription of fluoxetine. This drug can actually cause side effects, such as insomnia, anxiety, and headache [16]. However, we cannot rule out that the worsening of migraine in conjunction with fluoxetine had happened by chance.

This case is unique because the abuse of zopiclone and prazepam, documented by hair analysis, concerns a migraine patient without a history of drug addiction, alcoholism or psychiatric disorders other than insomnia. However, considering the widespread diffusion of sleep disorders among migraineurs, this case might not be the only one.

In conclusion, extreme caution and a careful management of the therapy are therefore needed when hypnotic and anxiolytic agents are prescribed to patients with chronic pain. Even if the chosen drugs have a low abuse liability on 
the basis of their pharmacological properties, they may be perceived by physicians as always safer [17], regardless of the individual's characteristics and milieu.

\section{Grant}

No.

\section{Conflict Interest}

The authors declare that they do not have any financial or other relationships that might lead to a conflict of interest. The authors declare that they do not have any sources of funding.

\section{References}

1. Ohayon MM. Relationship between chronic painful physical condition and insomnia. J Psychiatr Res. 2005;39(2):151-159.

2. Rains JC, Poceta JS. Sleep and headache. Curr Treat Options Neurol. 2010;12(1):1-15.

3. Manzoni GC, Stovner LJ. Epidemiology of headache. Handb Clin Neurol. 2010;97:3-22.

4. Headache classification subcommittee of the international headache society. The international classification of headache disorders, 2nd edition. Cephalalgia 2004;24(Suppl 1):9-160.

5. Evers S, Marziniak M. Clinical features, pathophysiology, and treatment of medication-overuse headache. Lancet Neurol. 2010;9(4):391-401.

6. Krystal AD. Treating the health, quality of life, and functional impairments in insomnia. J Clin Sleep Med. 2007;3(1):63-72.

7. Gaebel W. The importance of non-biological factors in influencing the outcome of clinical trials. Br J Psychiatry Suppl. 1993;22:45-50.

8. Goa KL, Heel RC. Zopiclone. A review of its pharmacodynamic and pharmacokinetic properties and therapeutic efficacy as an hypnotic. Drugs. 1986;32(1):48-65.

9. Hajak G. A comparative assessment of the risks and benefits of zopiclone: a review of 15 years' clinical experience. Drug Saf. 1999;21(6):457-469.

10. Lader M. Zopiclone: is there any dependence and abuse potential? J Neurol. 1997;244(4 Suppl 1):S18-22.

11. Pat-Horenczyk R, Hacohen D, Herer P, Lavie P. The effects of substituting zopiclone in withdrawal from chronic use of benzodiazepine hypnotics. Psychopharmacology (Berl) 1998;140(4):450-457

12. Jacqmin P, Ansseau M. Comparison of sublingual and oral prazepam in normal subjects. II. Pharmacokinetic and pharmacodynamic data. Neuropsychobiology. 1988;19(4):186-191.

13. Sugerman AA, Miksztal MW, Freymuth HW. Comparison of prazepam and placebo in the treatment of convalescing narcotic addicts. J Clin Pharmacol New Drugs. 1971;11(5):383-387.

14. Hering-Hanit R, Yavetz A, Dagan Y. Effect of withdrawal of misused medication on sleep disturbances in migraine sufferers with chronic daily headache. Headache. 2000;40(10):809-812.

15. Villain M, Cheze M, Tracqui A, Ludes B, Kintz P. Testing for zopiclone in hair application to drug-facilitated crimes. Forensic Sci Int. 2004;145(2-3):117-121.

16. Mackay FJ, Dunn NR, Wilton LV, Pearce GL, Freemantle SN, Mann RD. A comparison of fluvoxamine, fluoxetine, sertraline and paroxetine examined by observational cohort studies. Pharmacoepidemiol Drug Saf. 1997;6(4):235-246.

17. Siriwardena AN, Qureshi Z, Gibson S, Collier S, Latham M. GPs' attitudes to benzodiazepine and 'Z-drug' prescribing: a barrier to implementation of evidence and guidance on hypnotics. Br J Gen Pract. 2006;56(533):964-967. 